\title{
Study on caries prevalence and clinical performance of restorations applied on the first permanent molar
}

\author{
Studiu privind prevalenţa cariei şi performanţa clinică a \\ obturaţiilor aplicate la nivelul primului molar permanent
}

\author{
Mihaela Tănase, Ioana Stanciu, Daciana Zmarandache, Aneta Munteanu,Victor Feraru \\ Disciplina de Pedodonţie, Facultatea de Medicină Dentară, Universitatea de Medicină şi Farmacie \\ „Carol Davila“, Bucureşti, România
}

\begin{abstract}
The aim of the study was to evaluate the prevalence of dental caries (Ip), the treatment needs and the clinical performance of restorations applied on the first permanent molar (FPM) in a sample of patients, aged 6 to 10 years, over a period of 36 months.

Material and method. A longitudinal descriptive observational retrospective study was performed on a group of 367 patients (184 boys) aged 6-10 years, examined and treated at the Department of Paediatric Dentistry of the Faculty of Dentistry, „Carol Davila” University, Bucharest. It was determined: the number of affected FPM and their diagnosis, the type of treatment applied and the materials used, the time interval until restoration failure occurred and the possible causes of the treatment failure. For the clinical evaluation of the restorations (functional status of the restorations) was used modified RYGE criteria. The longevity of the restorations was evaluated for a period of 30 months. Periodic check-ups were carried out once every 6 months. Statistical data processing was obtained with the SPSS 18.0 program, for $p \leq 0.05$.

Results. The prevalence of carious lesions of the FPMs was $35.67 \%$, with a higher prevalence for the mandibular molars (SS, p <0.05). $29.88 \%$ of patients presented simple caries and $3.79 \%$ complicated caries. $91 \%$ of the FPMs were filled with glass-ionomer and resin-based composites and $9 \%$ with amalgam. The failure rate of the restorations was $22 \%$. The main causes of failure were: the fracture of the restoration and the loss of the marginal adaptation, with the appearance of the secondary caries and tooth discoloration.

Conclusions. The prevalence of dental caries on the FPM in the studied age group is high, the carious lesions being detected shortly after their eruption. The rate of successful treatment was $78 \%$. Failure occurred especially in the case of preventive resin restorations and glass-ionomer fillings. Regular dental follow-up is required and the restoration should be chosen taking into consideration the clinical situation (type and depth of the cavity)
\end{abstract}

Keywords: first permanent molar, carious lesion, filling

\section{REZUMAT}

Scopul studiului a fost evaluarea prevalenţei cariei dentare (Ip), a necesarului de tratament şi a performanţei clinice a obturaţiilor aplicate la nivelul molarului unu permanent (M1p) la un lot de pacienţi cu vârste cuprinse între 6 şi 10 ani, pe o perioadă de 36 de luni.

Material şi metodă. S-a realizat un studiu retrospectiv observaţional descriptiv longitudinal pe un lot de 367 pacienţi (184 băieţi) cu vârste cuprinse între 6 şi 10 ani, consultaţi şi trataţi în cadrul Clinicii de Pedodonţie a Facultăţii de Medicină Dentară, U.M.F „Carol Davila“ din Bucureşti. S-au determinat: numărul şi diagnosticul M1P afectaţi, tipul de tratament, materialele utilizate, intervalul de timp şi posibilele cauze ale eşecului tratamentului. Pentru evaluarea clinică a obturațiilor (statusului funcţional al restaurărilor) s-au utilizat criteriile RYGE modificate, longevitatea obturaţiilor fiind evaluată pentru o perioadă de 30 de luni, realizându-se controale periodice odată la 6 luni. Prelucrarea statistică a datelor s-a făcut cu programul SPSS 18.0, pentru $p \leq 0,05$.

Rezultate. Prevalenţa cariei la nivelul M1p a fost de 35,67\%, mai afectaţi fiind M1p inferiori $(S S, p<0,05)$. $29,88 \%$ au prezentat carii simple şi 3,79\% carii complicate. $91 \%$ dintre M1p au fost obturaţi cu CIS şi răşini compozite şi $9 \%$ cu amalgam. Rata de eşec a obturaţiilor a fost de $22 \%$, principalele cauze fiind: fractura obturației, pierderea adaptării marginale cu apariţia cariei secundare şi modificarea de culoare.

Concluzii. Prevalenţa cariei pe M1p la grupa de vârstă studiată este mare, leziunile fiind prezente foarte aproape de momentul erupţiei. Rata de succes a tratamentelor efectuate a fost de $78 \%$. Eşecul a apărut mai ales în cazul OPR şi al obturaţiilor cu CIS. Sunt necesare controale stomatologice regulate şi individualizarea aplicării obturaţiilor în funcţie de situaţia clinică (tipul de cavitate şi profunzime).

Cuvinte cheie: molarul unu permanent, afectare carioasă, obturaţie 


\section{INTRODUCERE}

Importanța molarilor 1 permanenți (M1p) în dezvoltarea aparatului dento-maxilar, afectarea precoce şi evoluția rapidă a cariei dentare la nivelul acestuia necesită instituirea unui tratament de refacere corectă morfo-funcțională a distrucției coronare (1). Cu cât refacerea se realizează mai devreme, cu atât creşte şansa de supravieţuire pe arcadă a acestui dinte. Experiența clinică arată însă că, de cele mai multe ori, micii pacienţi sunt aduşi la tratament destul de târziu, ceea ce periclitează, pe de o parte, vitalitatea dintelui şi, pe de altă parte, rezistenţa acestuia în timp (2).

Deoarece în România sunt studii relativ puţine privind comportamentul în timp al restaurării dinților permanenți cu diferite tipuri de materiale (3), în lucrarea de față se face un studiu asupra longevităţii obturațiilor fizionomice aplicate la nivelul M1P.

\section{SCOP}

Scopul studiului a fost evaluarea prevalenței cariei dentare (Ip), a necesarului de tratament şi a performanței clinice a obturațiilor aplicate la nivelul M1P la un lot de pacienți cu vârsta cuprinsă între 6 şi 10 ani, într-o perioadă de 36 de luni.

\section{MATERIAL ŞI METODĂ}

S-a realizat un studiu retrospectiv observațional descriptiv longitudinal pe un lot de 367 pacienți (184 băieți), cu vârste cuprinse între 6 şi 10 ani, consultați şi tratați în cadrul Clinicii de Pedodonție a Facultății de Medicină Dentară, U.M.F „Carol Davila“ Bucureşti.

Criteriile de includere ale pacienților în lotul de studiu au fost:

- vârsta cuprinsă între 6 şi 10 ani;

- cel puţin un M1p erupt pe arcadă;

- absența afecțiunilor generale asociate;

S-au exclus din lot pacienții cu M1p cu anomalii de dezvoltare tip hipomineralizare sau hipoplazie.

Metoda de lucru a constat în colectarea datelor din fişele clinice de tratament ale acestor pacienți:

- datele personale (nume, prenume, sex, vârstă);

- statusul eruptiv şi odontal al M1p;

- tipul tratamentului şi materialele utilizate la nivelul lui M1p;
- timpul şi posibilele cauze ale eşecului tratamentului.

Pentru evaluarea clinică a obturaţiilor (statusului funcțional al restaurărilor) s-au utilizat criteriile RYGE modificate, urmărindu-se următorii parametri: adaptare marginală, colorație marginală, culoare, stare de suprafață şi conturul anatomic. Longevitatea obturațiilor a fost evaluată pentru o perioadă de 30 de luni, realizându-se controale periodice o dată la 6 luni (4-7). Prelucrarea statistică a datelor s-a obținut cu programul SPSS 18.0, pentru $\mathrm{p} \leq$ 0,05 .

\section{REZULTATE}

Analizând statusul eruptiv al M1p în funcție de vârsta pacienților, se observă faptul că $46 \%$ dintre copiii în vârstă de 6-7 ani şi 71\% dintre cei în vârstă de 7-8 ani aveau M1p erupți (Fig. 1).

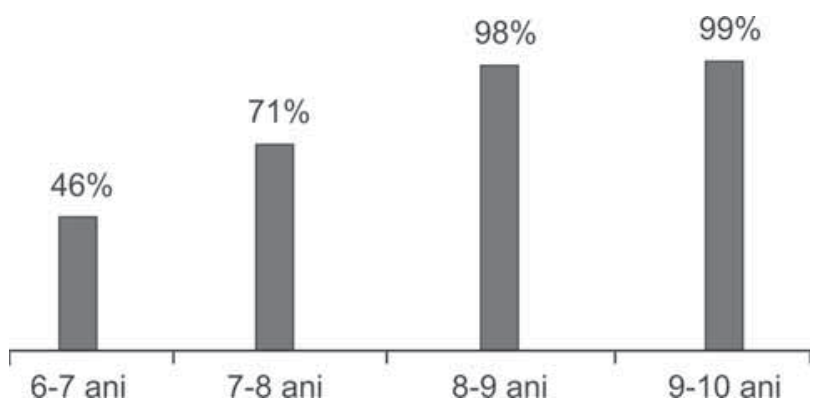

FIGURA 1. Distribuția lotului în funcție de vârstă şi statusul eruptiv al M1p

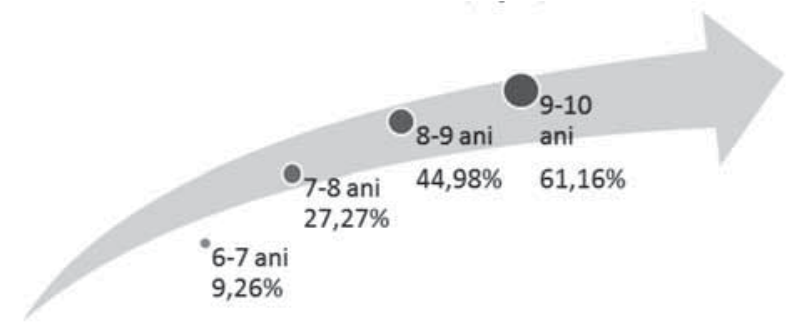

FIGURA 2. Prevalența cariei la M1P în funcție de vârstă

Numărul de M1p cariați/pacient a crescut, de asemenea, odată cu vârsta, astfel încât la 6-7 ani doar $6 \%$ dintre pacienți prezentau $4 \mathrm{M} 1 \mathrm{p}$ afectați, pe când la 9-10 ani 35\% aveau toți M1p interesați (Fig. 3).

M1p inferiori au fost semnificativ statistic mai afectați decât cei superiori $(\mathrm{p}<0,05)$ pentru toate grupele de vârstă. În general, atacul carios a fost simetric stânga-dreapta, cu excepția vârstei de 6-7 ani, la care M1p de pe partea dreaptă au fost mai 


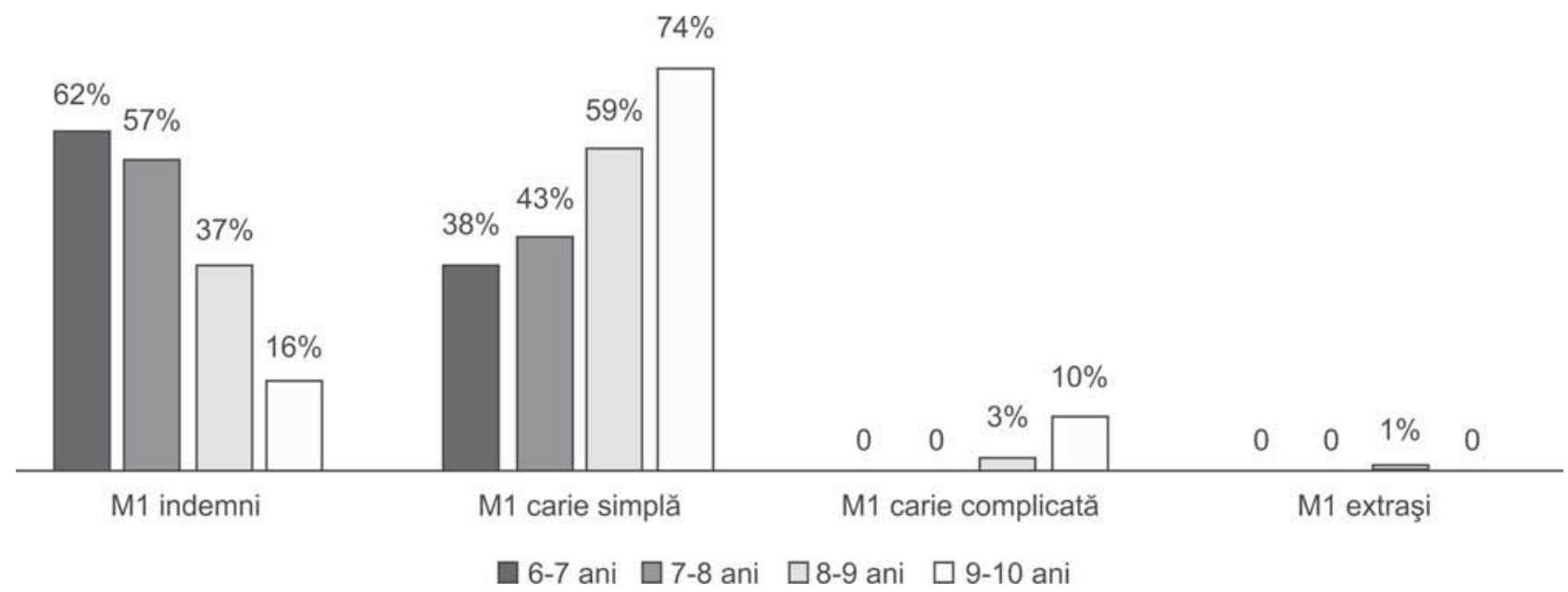

FIGURA 3. Distribuția M1p în funcție de statusul odontal

interesaţi decât cei de pe partea stângă, diferența fiind însă nesemnificativă statistic ( $\mathrm{p}>0,05)$.

$64,33 \%$ dintre M1p prezenți pe arcadă au fost indemni de carie, $29,88 \%$ au prezentat carii simple (15\% superficiale, $9,57 \%$ medii, 5,31\% profunde) şi 3,79\% carii complicate. $2,2 \%$ dintre pacienți au avut la prima prezentare cel puțin un M1p deja extras. Distribuția pe grupe de vârstă este prezentată în figura 3.

La nivelul întregului lot, 16,5\% dintre pacienți au prezentat un M1p cariat, 10,3\% au avut doi M1p cariaţi, 4,5\% au avut trei M1p cu leziuni carioase şi 4,3\% au prezentat toți cei patru M1p cariați (Fig. 4).

In ceea ce priveşte tipul de materiale folosite pentru obturarea cavităților de la nivelul M1p, cele mai folosite materiale au fost cimentul glassionomer si răşinile compozite, procentul fiind de aproximativ $45 \%$ pentru fiecare şi numai la $9 \%$ dintre pacienți s-a folosit amalgamul de argint.

Majoritatea cavităților realizate la nivelul M1p au fost cavități de clasa I (67\%), urmate de OPR tip
I (29\%), cavităţile tip MOD fiind realizate la doar 1\% dintre molari (Fig. 5).

Aproximativ jumătate dintre cavităţile realizate la nivelul M1p au avut adâncime medie, 14\% dintre ele fiind profunde şi $38 \%$ superficiale.

După intervalul de 36 de luni, rata de succes a obturațiilor aplicate la nivelul M1p a fost de $78 \%$. $22 \%$ dintre obturații au necesitat refacerea lor, cea mai mare rată de eşec fiind înregistrată în cazul obturațiilor din ciment ionomer de sticlă $(13 \%)$, iar cea mai mică în cazul amalgamului $(0,06 \%)$ (Fig. 6).

Rezultatele clinice cele mai slabe le-au avut OPR1 (32\% trebuind să fie refăcute) şi obturațiile din cavitățile superficiale $-27 \%$ dintre obturații au necesitat refacere (Fig. 7).

Cauzele eşecului au fost: fractura obturaţiei (35$7 \%$ pentru compozit, $26 \%$ pentru CIS si $2 \%$ pentru amalgam), pierderea adaptării marginale cu apariția cariei secundare (32\%-9\% pentru compozit, $21 \%$ CIS şi $2 \%$ amalgam) şi modificarea de culoare $(36 \%)$.

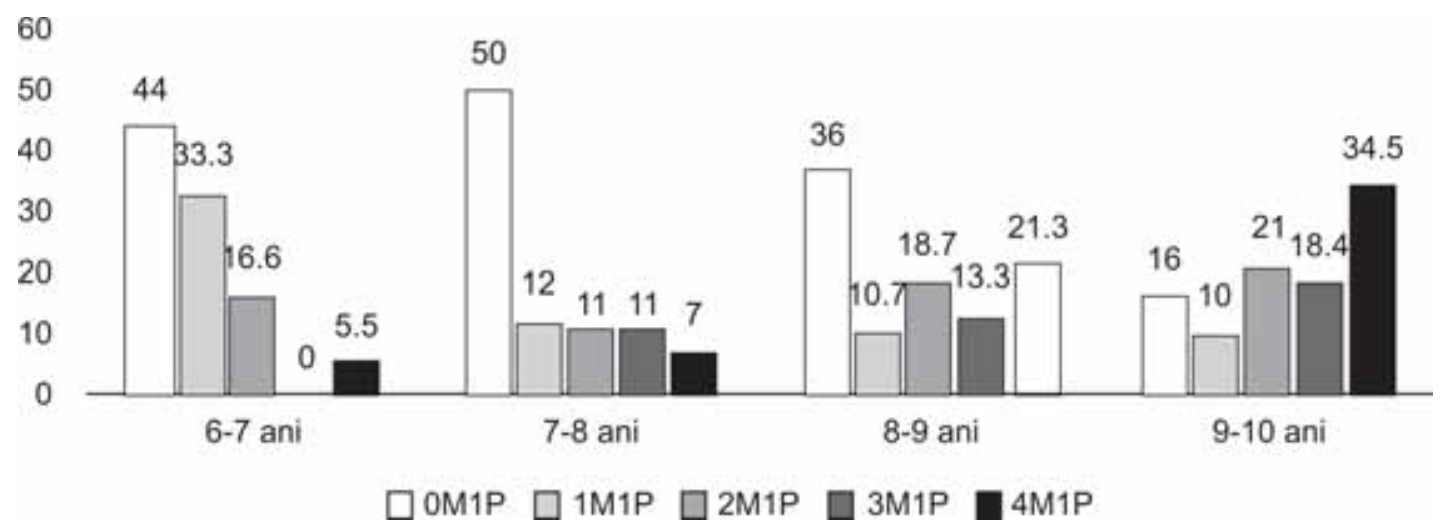

FIGURA 4. Distribuția afectării M1p pe grupe de vârstă 


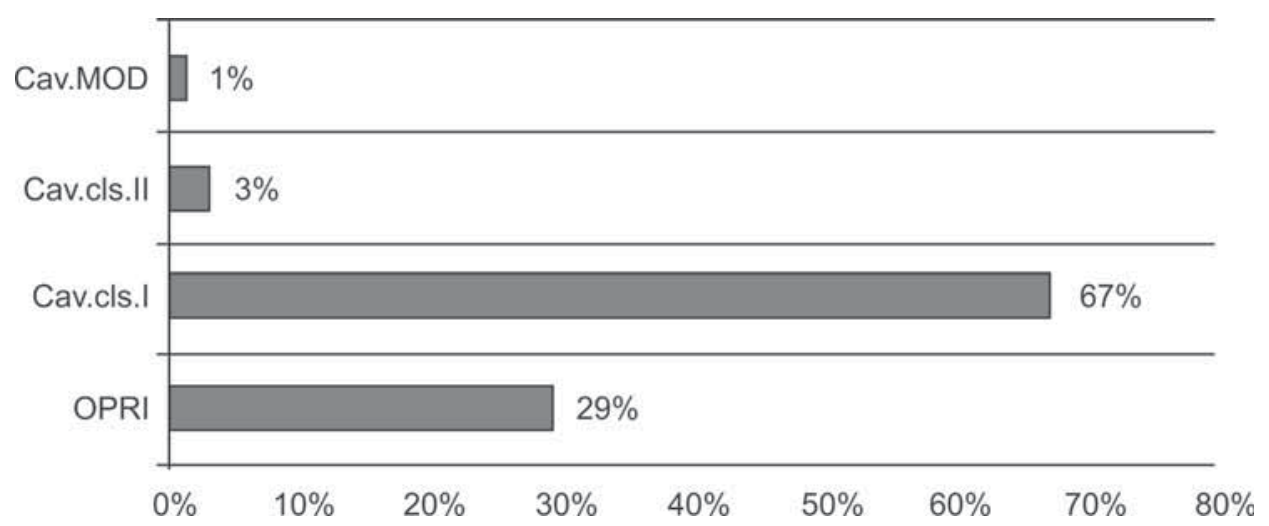

FIGURA 5. Distribuția M1P în funcție de tipul de cavitate realizată

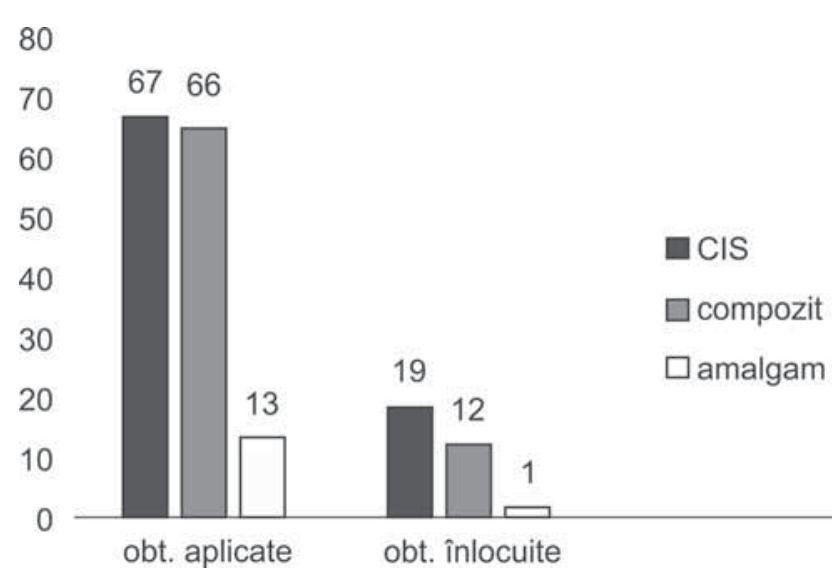

FIGURA 6. Distribuția obturațiilor aplicate şi refăcute

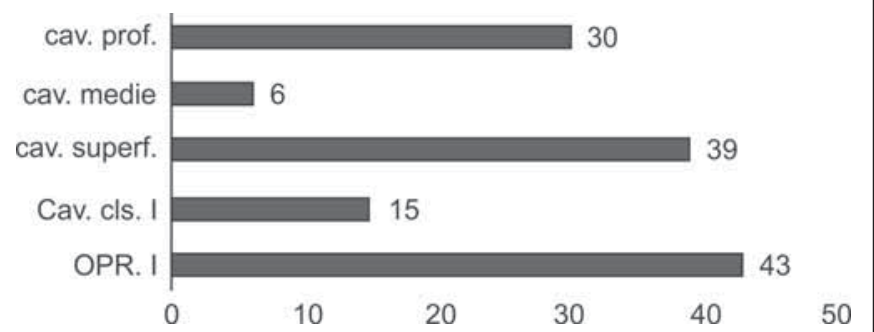

FIGURA 7. Distribuția obturațiilor eşuate în funcție de tipul cavității şi adâncime
În ceea ce priveşte durata de timp, fracturile obturațiilor (indiferent de materialul de obturație) au apărut în primele 6 luni de la aplicarea obturațiilor, când s-au produs $70 \%$ din totalul fracturilor. Cariile secundare au apărut la aproximativ $2 \frac{1}{2}$ ani de la aplicare la 53\% dintre obturațiile aplicate. Legat de recidiva cariei, rezultatele studiului nu au fost relevante (Fig. 8).

\section{DISCUŢII}

Studiul afectării prin carie la nivelul M1p la lotul studiat a arătat o prevalență crescută a leziunilor carioase, acestea fiind prezente foarte aproape de momentul erupției. Rezultatele obținute sunt comparabile cu cele raportate de Ali şi col. (2013), dar mai mari decât cele din studiile Togoo şi col. (2011) şi Abuaffan şi col. (2018) (Tabelul 1).

La nivelul întregului lot, 16,5\% dintre pacienți au prezentat un M1p cariat, 10,3\% - 2 M1p cariați, 4,5\% - 3 M1p cu leziuni carioase şi 4,3\% - toți cei patru M1p cariați. Rezultate asemănătoare au obținut şi Ali şi col., în 2013 (Tabelul 2).

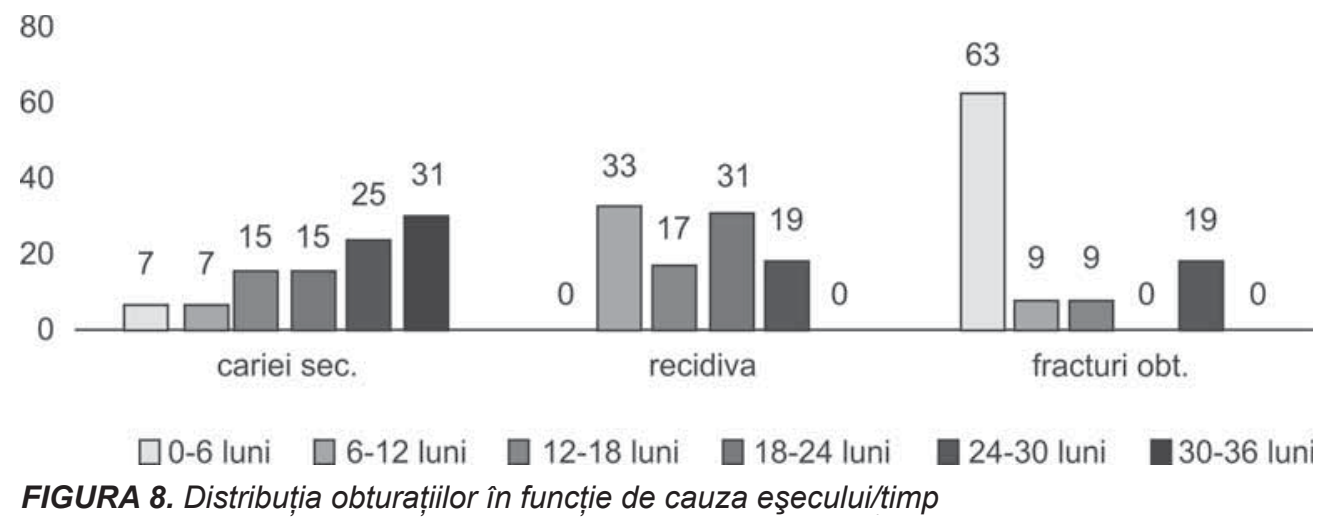


TABELUL 1. Prevalența cariei la nivelul lui M1p

\begin{tabular}{|l|l|c|c|c|c|}
\hline Autori & Tara & Lot & $\begin{array}{c}\text { Vârsta } \\
\text { (ani) }\end{array}$ & $\begin{array}{c}\text { Copii cu carii } \\
\text { pe M1p }\end{array}$ & $\begin{array}{c}\text { Copii fără } \\
\text { carii pe M1p }\end{array}$ \\
\hline Ali şi col., 2013 (7) & Pakistan & 447 & $8-12$ & $30,6 \%$ & $69,4 \%$ \\
\hline Togoo şi col., 2011 (9) & Arabia Saudită & 836 & $7-10$ & $66,4 \%$ & $33,6 \%$ \\
\hline Abuaffan şi col. 2018 (8) & Sudan & 300 & $6-14$ & $61 \%$ & $39 \%$ \\
\hline Studiul prezent & România & 367 & $6-10$ & $35,67 \%$ & $64,33 \%$ \\
\hline
\end{tabular}

TABELUL 2. Numărul M1p cariați/pacient - rezultate comparative

\begin{tabular}{|c|c|c|c|c|c|c|c|}
\hline \multirow[t]{2}{*}{ Autori } & \multirow[t]{2}{*}{ Țară } & \multirow[t]{2}{*}{ Lot } & \multirow{2}{*}{$\begin{array}{l}\text { Copii cu toți M1p } \\
\text { indemni }\end{array}$} & \multicolumn{4}{|c|}{ Copii cu M1p cariați } \\
\hline & & & & $1 \mathrm{M} 1 \mathrm{p}$ & 2 M1p & 3 M1p & $4 \mathrm{M} 1 \mathrm{p}$ \\
\hline Ali şi col., 2013 (7) & Pakistan & 447 copii (8-12 ani) & $69,3 \%$ & $15,9 \%$ & $11 \%$ & $2 \%$ & $1,8 \%$ \\
\hline Studiul prezent & România & 367 copii (6-10 ani) & $64,33 \%$ & $16,5 \%$ & $10,3 \%$ & $4,5 \%$ & $4,3 \%$ \\
\hline
\end{tabular}

În studiul prezent, procentul de M1p cariați a crescut cu vârsta, o tendință similară fiind raportată şi de Togoo şi col. (9) (Tabelul 3).

M1p inferiori au fost semnificativ statistic mai afectați decât cei superiori $(\mathrm{p}<0,05)$ pentru toate grupele de vârstă la lotul studiat. Rezultatele concordă cu cele obținute de Togoo şi col. în Arabia Saudită, care au raportat $35,9 \%$ M1p cariați la maxilar şi 50,8\% M1p cariați la mandibulă $(p<0,001)$ (9). O afectare mai mare a M1p inferiori s-a observat şi în studiul lui Ali şi col. din anul 2013, realizat în Pakistan: 18,34\% copii cu carii pe M1p maxilari şi 33,33\% copii cu carii pe M1p mandibulari (7). De asemenea, Abuaffan şi col. în anul 2018, pe un lot de studiu de 300 copii de 6-14 ani, au observat faptul că M1p mandibulari au fost mai afectați decât cei maxilari (8).
Comparând rata de succes a restaurărilor adezive obținută în studiul de față cu rata de succes a altor autori, se observă faptul că o rată mai mare de succes au obținut Granath şi col., Welburry şi col. şi Walker şi col., ceilalţi autori având o rată de succes mai mică decât cea din studiul prezent (Tabelul 4).

\section{CONCLUZII}

1. Prevalența cariei pe M1p la grupa de vârsta studiată a fost crescută, leziunile carioase fiind prezente foarte aproape de momentul erupției. 2. Rata de succes a tratamentelor efectuate a fost de $78 \%$. 3. Eşecul a apărut mai ales în cazul OPR şi al obturațiilor cu CIS. 4. Sunt necesare controale stomatologice regulate pentru prevenirea apariției cariei dentare la nivelul lui M1p şi individualizarea apli-

TABELUL 3. Distribuția M1p cariați pe grupe de vârstă

\begin{tabular}{|l|l|l|c|c|c|c|}
\hline Autori & Țara & Lot de studiu & \multicolumn{4}{|c|}{ \% M1p cariați } \\
\cline { 4 - 6 } & & & $\mathbf{7}$ ani & $\mathbf{8}$ ani & $\mathbf{9}$ ani & $\mathbf{1 0}$ ani \\
\hline Togoo şi col., 2011 (9) & Arabia Saudită & 836 copii, 7-10 ani & $14,4 \%$ & $35,8 \%$ & $56,9 \%$ & $60,1 \%$ \\
\hline Studiul prezent & România & 367 copii, 6-10 ani & $9,26 \%$ & $27,27 \%$ & $44,98 \%$ & $61,16 \%$ \\
\hline
\end{tabular}

TABELUL 4. Rata de succes a obturațiilor aplicate pe M1p

\begin{tabular}{|l|c|c|c|}
\hline Autori & $\begin{array}{c}\text { Rata de succes pentru } \\
\text { restaurări adezive }\end{array}$ & Timp & Lot de studiu \\
\hline Rafatjou și col., 2014 (11) & $53,6 \%$ & 1 an & 57 copii, 7-13 ani \\
\hline $\begin{array}{l}\text { Subramyana și col., 2006 } \\
\text { (12) }\end{array}$ & $7,5 \%$ & 1 an & - \\
\hline Welburry și col., 1990 (13) & $95 \%$ & 5 ani & - \\
\hline Walkers și col., 1996 (14) & $83 \%$ & 6,5 ani & - \\
\hline Granath și col., 1992 (15) & $97,6 \%$ & 2 ani & 111 copii, 5-14 ani \\
\hline Houpt și col., 1994 (15) & $31 \%$ & 9 ani & 110 copii, 6-14 ani \\
\hline Raadal, 1978 (15) & $83 \%$ & 30 luni & 281 copii, 5-7 ani \\
\hline Pandiyan și col., 2016 (10) & $62,2 \%$ & 2 ani & 61 copii, 6-10 ani \\
\hline Kilpatrick și col., 1996 (15) & $78,5 \%-$ compozit 59,1\% - & 17 luni & 67 copii \\
\hline Gray și col., 1994 (15) & $30,9 \%$ pt CIS & 1 an & vârsta medie 11 ani \\
\hline Studiul prezent & $78 \%$ & 3 ani & 367 copii, 6-10 ani \\
\hline
\end{tabular}


cării obturațiilor în funcție de situația clinică (tipul de cavitate şi profunzime).
Notă: Autorii au contribuit în mod egal la prezentul articol, de aceea toți sunt considerați autori principali.

Conflict of interest: none declared

Financial support: none declared

\section{BIBLIOGRAFIE}

1. Chukwu GA, Adeleke OA, Danfillo IS, Otoh EC. Dental caries and extraction of permanent teeth in Jos, Nigeria. African Journal of Oral Health. 2004;1(1): 31-6.

2. Luca R, Gorduza A, Tănase M. Observaţi clinice asupra obturaţiilor cu ionomer-acril. Studiu preliminar. Stomatologia (Bucureşti) 1999, XLV(2): 48-54.

3. Barnes DM, Blank LW, Gingell JC et al. A clinical evaluation of a resin-modified glassionomer restorative material. J.A.D.A.1995: 1245-53.

4. Blum IR, Lynch CD, Schriever A et al. Repair versus replacement of defective composite restorations in dental schools in Germany. Eur J Prosthodont Restor Dent 2011,19: $56-61$.

5. Braga SR, Vasconcelos BT, Macedo MR et al. Reasons for placement and replacement of direct restorative materials in Brazil. Quintessence Int. 2007, 38: 189-94.

6. Burke FJ, Cheung SW, Mjör IA et al. Restoration longevity and analysis of reasons for the placement and replacement of restorations provided by vocational dental practitioners and their trainers in the United Kingdom. Quintessence Int 1999, 30: 234-42.

7. Ali SN, Ali SN, Khan M et al. Prevalence of dental caries in the first permanent molars in children between 8-12 years. $J$ Pak Dent Assoc 2013, 22(2): 119-23.

8. Abuaffan AH, Hayder S, Hussen AA et al. Prevalence of dental caries of the first permanent molars among 6-14 years old Sudanese children. Indian Journal of Dental Education 2018, 11(1): 13-6.

9. Togoo RA, Yaseen SM, Zakirulla M et al. Prevalence of first permanent molar caries among 7-10 years old school going boys in Abha City, Saudi Arabia. J Int Oral Health 2011, 3(5): 29-34.

10. Pandiyan NJ, Hedge A. A clinical comparison on success of sealant and preventive resin restoration on caries prevention. Malaysian Journal of Applied Sciences 2016, 1(2): 71-7.

11. Rafatjou R. Mashad N, Shokoufeh N et al. Assessment of the success rate of conservative adhesive resin restoration (CAR) in first permanent molar teeth treatment in Hamadan, Iran. American Journal of Clinical and Experimental Medicine 2014, 2(4): 74-8.

12. Subramanya P. An in vivo comparative stud of preventive restoration and glass-ionomer preventive restoration in young permanent teeth school dental health program. Disertation. Bangalore. Raliv Ghandi University of Health Sciences, 2006.

13. Welburry RR, Walls A, Murrag JJ et al. The management of occlusal caries in permanent molar. A five-year clinical trial comparing a minimal composite with amalgam restoration. $\mathrm{Br}$ Dent J 1990, 169(11): 361-6.

14. Walker JD, Floyd K, Jakobson J et al. The effectiveness of preventive resin restoration in pediatric patients. J Dent Child 1996, 63: 338.

15. McComb D. Systematic review of conservative operative caries management strategies. Journal of Dental Education2001 65: 1154-61. 